CASE OF INTRA-UTERINE TUMOUR. By T. OGIER WARd, M.D.

TO THE EDITOR OF THE PROVINCIAL MEDICAL AND SURGICAL JOURNAL.

Sir,

I beg leave to forward to you the enclosed comnunication, which I received last week, with the desire that it should be sent to you,

\section{And I remain, Sir,}

Your obedient servant, WILLIAM THOS. HAMILTON.

Birkenhead, August 6th, 1844.

Having read in the Provincial Journal of yesterday your case of Intra-uterine Tumour, I venture to send you an imperfect history of a somewhat similar case that $I$ have met with, in the hope that, by comparing notes, we may be enabled to throw some light upon the nature and origin of these formations.

In February last $I$ was requested to see a poor woman, aged 45 , who was said to be dying, when I found her suffering from violent and almost incessant purging and voniting of a yellow feculent fluid, like thin gruel, in alternate attacks, recurring every two or three days. She was much wasted; complexion like a gipsy's, eyes staring, countenance anxious, tongue furred and dry, incessant thirst, pulse rapid and feeble. Besides the vomiting, she complained of intense pain over the whole abdomen, which was exquisitely tender to the touch. The lower part from the navel was occupied by a firm round tumour, without fluctuation, though rather elastic, and sounding dull on percussion. She told me she had been twice married; had one child by her first husband, and miscarried about six months before; since then she had been regular, till about three months ago, when she first perceived a small tumour in her left flank, which had gradually increased till it acquired its present size and place; and during this time her health had become impaired, though her present symptoms were only of three weeks continuance. There was some discrepancy between her account and that of her husband and neighbours respecting the first appearance of the tumour and her last menstrual period, for she seemed to have lost her recollection in a great degree, and was often delirious. On examination, per vaginam, I found the os uteri smooth, firm, and closed, projecting forwards into the vagina, as though the body were pressed down into the hollow of the sacrum, but there was no indication of the presence of any tumour in connexion with the uterus, nor did it give the idea that it was enlarged. The form of the tumour, its position, and the closure of the os uteri, together with the recent miscarriage and cessation of the menses, induced an opinion that it might be a case of pregnancy, or hydatids, or serous cysts, while the woman's account of its origin, and the ideas of her husband and her friends rendered it more probable that it was ovarian disease; at the same time the extreme pain and tenderness, the vomiting and purging, with fever and delirium, led me to suspect it might be an acute affection of the peritoneum, though the altered complexion was indicative of cancer. Not being satisfied with any of these reasonings, and believing that if not relieved, she would die in a few days, as I found medicine had no power to arrest the vomiting and purging, I determined to explore the nature of the tumour with a small trocar, thinking, that if there were a fœtus or mole, it would be expelled, and thus only one life might be sacrificed, and if a cyst, it would be evacuated.

The instrument seemed to pass into a firm substance, and upon withdrawing the trocar, about half a pint of rather gelatinous, brown fluid followed, when the canula became obstructed by a white greasy matter, resembling that which covers the bodies of new-born infants, and like that consisting of epithelial scales. The operation gave great relief to all the symptoms for a time, but they recurred in about ten days, with their former obstinacy, though not with equal violence. She then became an inmate of the poor-house, and died at the end of March. Her body was examined, and the gentlemen who presided gave me the following account : -There were only slight vestiges remaining of the left ovary; the os uteri was quite scirrhous, but not ulcerated nor tuberculated. The uterine cavity was filled with a white steatomatous matter, containing a lock of hair. There was no appearance of a cyst, nor any fluid round it, and the nterine wall varied from 1-4 th to 1-8th of an inch in thickness. The mass was as large as a child's head of a year old. The rectum adhered to the uterus, but there were no marks of peritoneal inflammation, nor any adhesion of the uterus to the abdominal parietes at the place where it had been punctured. I ought to add that the gentleman who conducted the inspection knew nothing of the history of the case previous to the adnission of the patient into the poor-house.

This case presents several points of interest, both physiological and practical.

1. I am not aware that any person has noticed that the white substance that covers new-born infants consists mainly of epithelial scales, mingled with a saponaceous matter; and it appears to me that if you can find them among the steatomatous mass described in your letter, it will go far to prove that they are not a product of the fotal epidermis, but a uterine secretion. This point you will easily ascertain by a comparison of the two, with the aid of a microscope of ordinary power.

2. It also establishes the fact, that the distended uterus may be punctured, and some of its contents withdrawn, not only without producing any expulsive efforts, but with decided relief to the symptoms arising from that distension; for, as there were no marks of peritoneal or otherinflammation, I cannot but consider that the tenderness, pain, vomiting, purging, and prostration, were sympathetic only of the uterine irritation, and that, not of the os tincæ, which, though scirrhous, was never prominently painful, but of the body of the womb.

3. The presence of a lock of hair proves that there must have been a nisus formativus in the first instance; and if we suppose that this produced-as is likelyincreased action in the uterus, the researches of $\mathbf{M r}$. Addison would in some degree support the notion, that the action of an effete uterus might, be abnormal, and that a vast formation of epithelial scales instead of the ordinary membranes, might be the result; or, what is more propable perhaps, that the membranes enveloping the tuft of hair received no accession from the uterus, while the epithelial secretion was inordinately 
siadanow, ond enveloped them in a thick mass. I have mit with no case of aterine serous cysts since this case occurred, to be enabled to remark whether their surface exhibits epithelial scales.

4. The secretion of epithelium in this case must have been enormous, for all parties agreed that the tumour could not have been above five months in acquiring its size, when I first saw her.

5. The ages of both cases agree with that of most persons whom I have remarked with uterine serous cysts, which, like the present, I look upon as the last abortive efforts of the reproductive function previous to its perfect cessation.

6. The strongly marked symptoms of the last stage of peritoneal inflammation, before what used to be termed the stage of gangrene, might have induced me to use powerful antiphlogistic treatment, had I seen her before her strength became exhausted; and yet I should have committted a grievous error; and this, nowithstanding $I$ tried to guard against mistake, by varying my mode of pressure, secundum artem, over the tumour and other parts of the abdomen. The chest was not tender. By the way, let me ask whether you find gangrene in all cases of fatal peritonitis where the pain subsides before death ? I must say $I$ do not; and even after the operation for hernia, the. gangrene is rarely very extensive where it exists at all, and never equally so as the attending inflammation.

7. The ileus alternating with colliquative diarrhoa, without, local disease of the bowels, (if we except the adhesions of the rectum to the uterus,) is also interesting, particularly as neither symptom was relieved by any mode of treatment, except by the puncture and unloading of the uterus.

I should not have thought my single case worth publishing, had not the similarity of yours, and the paper of Mr. Addison appearing in the same number of the Journal, induced me to think that if the examination of your preparation supports my views, this letter, enriched by your observations, may afford an interesting confirmation to the theoretic portion of $\mathrm{Mr}$. Addison's valuable writings on the subject of nutrition. At all events I shall feel obliged by your forwarding it to Dr. Streeten, with or without any additions of your own; and for thus troubling you I must plead non omnia possumus omnes, and remain,

Your obliged,

T. OGIER WARD.

21, Philimare Place, Kensington August 1, 1844.

\section{PROVINCIAL}

\section{fteđical \& Eurgícal Journal.} WEDNESSAY, SEPTEMBER 4, 1844.

We hast weck inserted some observations on the removal of atl restrictions from the practice of medicine by unqualified and incompetent persons, which forms so prominent a feature of Sir James Graham's Bill. In our present number will be faund:an expression of opinion on the same subject, and on some other parts of the measure, by two important meetings, which at this early period have already been held in different parts of the country. It is a fortunate circumstance that from the late introduction of the Bill into the House of Commons, it is impracticable that it should during this Session be carried through its several stages, so as to become a part of the law of the land. Time is thus allowed for a consideration of its provisions by the whole medical profession, and for the expression of opinion with regard to the merits or demerits of the leading points, and on the machinery by which it is intended to be rendered effective. The example of the Warwickshire and the Surrey practitioners will, we trust, be followed by the members of the profession resident in other counties, and in the larger and more populous towns, and it cannot be doubted but that the general agreement which we believe to exist amongst all classes of the profession, on certain parts of the measure, must have some effect.

It is highly desirable that this, and indeed ans measure on the subject, should be regarded in the twofold character of its relation to the public welfare, and its bearing on the interests of the medical profession. The profession have a right to expect that, as far as is consistent with the former of these objects-the public welfare-their own views of the management of their own concerns should be at least considered and treated with respect. No extra-professional individual, however bighly he may be otherwise qualified, is competent to judge of what is best and most fitting for the regulation of maitters of which he is by education, or rather by want of education and due information, necessarily ignorant. We will even go farther, and say that no one professional person can of himself know what the wants of the whole profession require, and to follow or be guided solely by the opinion of London practitioners as to the state of medical practice, and the requirements of medical polity in the prorinces, or of provincial practitioners as to the medical wants of metropolitan towns, müst inevitably lead to error, and give rise to dissatisfaction.

As far, therefore, as regards the internal regulation of its concerns, the whole medical profession, not one portion of it alone nor merely one or two selected individuals, ought to have beenconsulted and have a right to be beard. As far as the putblic welfare is concerned,although the Government and the Legislature may possibly be, creteris parribits, the best judges, yet do we think that true wisdom should lead those in power to listen to those who are better qualified to form an opinion in some points at least than themselves. The removal of restraints from empirical practice we believe to be more detrimental, to be fraught with more danger, to the public in general, than infurious to the interests of the medical profession. It is especially 